\title{
INFLUÊNCIA HIDROLÓGICA NO SINAL DO GRAVÍMETRO GPHONE
}

\author{
Ferreira, L. ${ }^{1}$; Marotta, G. S. ${ }^{1}$
}

Observatório Sismológico/Instituto de Geociências/Universidade de Brasília ${ }^{1}$

Copyright 2021, SBGf - Sociedade Brasileira de Geofísica.

This paper was prepared for presentation during the $17^{\text {th }}$ International Congress of the Brazilian Geophysical Society held in Rio de Janeiro, Brazil, $16-19$ August 2021.

Contents of this paper were reviewed by the Technical Committee of the $17^{\text {th }}$ International Congress of the Brazilian Geophysical Society and do not necessarily represent any position of

the SBGf, its officers or members. Electronic reproduction or storage of any part of this paper for commercial purposes without the written consent of the Brazilian Geophysical Society is prohibited.

\section{Abstract}

A influência das águas subterrâneas no ciclo hidrológico tem sido estudada em larga escala na Bacia Amazônica, um dos maiores reservatórios de água doce do mundo. Considerando a importância desta bacia no ciclo hidrológico global, estudos locais também são fundamentais. Então, foi realizado um estudo local do ciclo hidrológico em Manaus, no centro da Bacia Amazônica.

Foram utilizados dados da variação local de gravidade coletados com o gravímetro Micro-g LaCoste gPhone operando a uma taxa de amostragem de 1 segundo por 646 dias de 26 de janeiro de 2016 a 1 de novembro de 2017. Gravímetros têm sido amplamente usados para estudos de efeitos hidrológicos em escala local. No entanto, muitos estudos anteriores utilizam os chamados Gravímetros Supercondutores, que possui uma maior precisão quando comparado ao gPhone. Mais recentemente, medidores que usam o sistema de mola e mais baratos, como o gPhone, têm sido utilizados para o mesmo propósito.

No tratamento dos dados gravimétricos observados, para extração de informações relativas à influência hidrológica, foram consideradas as correções de carga atmosférica, de movimento do polo, de maré terrestre e oceânica. A correção da carga atmosférica considerou as variações de pressão externa registradas pelo gravímetro; a correção de movimento do polo considerou os parâmetros disponibilizados pelo International Earth Rotation and Reference Systems Service (IERS ) e a formulação definida no Absolute Observations Data Processing Standards (1992), especificada na International Absolute Gravity Basestation Network (IAGBN ); as correções de maré terrestre e oceânica seguiram recomendações e formulações apresentadas na nota técnica no 36 do IERS, sendo que, no caso de carga oceânica, foram utilizados parâmetros calculados provenientes do modelo FES2004 (Lyard et al., 2006), com $0.125^{\circ}$ de resolução.

Além das correções já citadas, os dados também foram corrigidos de efeitos de origem instrumental e natural (eventos sísmicos). Estas correções envolveram a variação do nível do instrumento, a deriva instrumental e os efeitos na série temporal observada, como saltos causados por interrupção de funcionamento do equipamento e dados espúrios causados por variação brusca do valor observado em função de efeitos instrumentais ou naturais. No caso da estimativa e correção do efeito de saltos e de deriva instrumental, foi considerada a aplicação do Método dos Mínimos Quadrados.

Diante do exposto, foi possível extrair as informações de variação do campo de gravidade correspondente à variação hidrológica. Após o processamento, a variação da coluna de água foi determinada a partir da variação da gravidade local e resultou em um valor próximo à variação observada em um poço próximo. 